\title{
Construction planning of low-rise residential property based on improving mobility of construction operations
}

\author{
Boris Khrustalev $^{1 *}$, Iuliya Artamonova ${ }^{1}$, Denis Zhelikhovsky ${ }^{1}$ and Daniil Osipov ${ }^{2}$ \\ ${ }^{1}$ Penza State University of Architecture and Construction, Titov St., 28, Penza, 440028, Russia \\ ${ }^{2}$ Astrakhan State University, Tatischev Str., 20a, Astrakhan, 414056, Russia
}

\begin{abstract}
Article discusses the possibility of implementing new modern tools and methods of construction operations. It esteems the main features of the scientific construction planning when building low-rise residential property and analyzing complex economic situations of companies operating under mobility conditions. It concludes that the choice of modern ways of construction planning increases the efficiency of the whole system of decision-making in this field.
\end{abstract}

\section{Introduction}

Inline building and construction allows accelerating the residential property delivery. At the same time, the previously erected industrial and social facilities of built-up areas and the infrastructure will be used to the maximum in the construction of real estate property and housing communities.

Despite the economic development of the regions in the European part of Russia, it should be mentioned that the initial phase of housing community building involves the integrated urban development. This means the development of transport links, the main engineering networks, the fuel and energy base, the material and technical base of construction, and household services. There are also such challenges as high cost and low efficiency of labor and labor shortages at large.

\section{Review}

When erecting suburban real estate and housing communities it is impossible that workers move long distance on the shift basis from the main base of the building organization to the construction sites. The facilities at the construction sites might differ sharply from each other.

The transfer of work force from one site to another can be carried out in two ways:

"demographic mobility" (new people are hired and the required number of construction crew units are created at each site of construction or sent to this new area);

"industrial mobility" (permanent mobile construction crew units of the construction company move from one site to another).

\footnotetext{
* Corresponding author :hrustalev_bb@mail.ru
} 


\section{Problem statement and research}

Regional building complex is sophisticated operating system developing horizontally and vertically. Housing communities are usually erected far from each other. If the distance between them and the construction base is too long, it is inefficient to use the same construction crew units working on the shift basis. The working conditions in each site might also be different from each other.

Transfer of people under demographic mobility works both ways:

- On the positive side is it accelerates the process of people relocation from one region of the country to another one and it is one of the existing methods of developing new regions;

- On the negative side is if this process is poorly prepared, it does not always produce desire effect.

This method can be characterized by huge costs for the creation of social infrastructure and facilities near the construction sites. On the one hand, demographic mobility of work resources contributes to maximizing the actual labor time reserve of workers, since it requires the adequate transport costs for moving workers, but, on the other hand, the whole cost of this type of mobility reaches significant values.

Another method, "industrial mobility" in comparison with the first one has a number of significant advantages, especially when it is necessary to keep the cluster of construction crew units for a certain period. It makes the industrial mobility highly effective in these conditions.

For instance, significant costs of creating and developing social facilities near construction sites are being cut; the level of professional skills of mobile crews is much higher than that of employees hired for one project, people live with families in ordinary environment.

In the system of construction operations, mobile crews (part of the system) have their own peculiarities:

- firstly, the frequent change of work and the constantly changing social infrastructure lead to the fact that the adaptation of a person to new environment requires a longer time than to the means of production;

- $\quad$ secondly, the development of social facilities affects only the person, since he wants to satisfy not future ('postponed') needs, but current ones that determine his daily life and performance;

- thirdly, when erecting low-rise residential property in conditions of mobility, the flow of material and technical resources is largely determined by their delivery to the construction sites. They can quickly be distributed and accumulated in any region of the country, being secured for the entire period of construction.

The development of low-rise residential property should be based on the implementation of the following principles:

1. Building constructor elaborates risk management models and evaluates uncertainty at each stage of building cycle. In this case, it is necessary to develop basic economic solutions aimed at reducing losses in operating processes.

2. Companies of investment and construction sectors increase their mobility. To this end, it is necessary to create normal conditions for technical, material, information, financial support for the company performance.

3. Companies as single units and the whole construction complex develop marketing departments. After finishing marketing research, it should be done on all fronts to implement the efficient management and create reasonable conditions. 
4. The construction sector shifts to space-planning decisions and construction solutions. In this case it is necessary to develop a set of economic, organizational and social measures. It can be done through the transition to new design and planning concepts.

5. Efficient forms of management and technologies of inline method of building are applied. A set of relevant measures and decisions should be elaborated and the transition to mobile schemes should be made (shifts, expeditions, expeditionary-shift method).

6. The companies of construction complex create an environment to attract investments. The constituent elements are as follows

- establish the network of permanent investors both within the region and outside it;

- develop a system of mobile construction crew units,

- stitch together companies capable of building various construction projects in all regions of Russia and abroad.

It helps to create a powerful potential and increase the level of efficiency.

Each of the areas of low-rise housing construction based on the implementation of a large set of tasks, requires the development of appropriate programs, actions, regulatory and legal documents, financial and investment frameworks. The implementation of these tasks should be carried out by steps, taking into account the prospects for the development of the entire construction complex.

The effectiveness of low-rise housing construction depends largely on the mobility of construction operations. The mobility of the construction system for the use of labor resources is understood as the ability of its units to migrate in certain areas of construction and to be accumulated in the necessary amount quantity. These units conduct themselves as functional elements and specialized crews. They can function efficiently in specific conditions when constructing or updating facilities in order to deliver this real estate property in a specified time with minimum labor costs.

To quantify the impact of mobility conditions and uncertainties in construction operations, we should take into account all three states of the development of the construction system. To calculate this impact to the activities of specialized subdivisions that operate flows in the main building-and-erection processes we consider the degree of mobility of the construction units at the technological conversion of the erection processes and apply the following formula:

$$
K_{M_{i}}^{\left(G_{i}\right)}=\frac{\sum_{\gamma=1}^{k} \sum_{i=1}^{n} \sum_{j=1}^{m} K_{G R_{i}}^{\left(P_{1} ; P_{2} ; P_{3}\right)} \times K_{G N_{i}}^{\left(P_{1} ; P_{2} ; P_{3}\right)} \times V_{i j \gamma}}{K_{G R_{i N}}^{\left(P_{1} P_{2} ; P_{3}\right)} \times K_{G N_{i N}}^{\left(P_{1} ; P_{2} ; P_{3}\right)} \times \sum_{\gamma=1}^{k} \sum_{i=1}^{n} \sum_{j=1}^{m} V_{i j \gamma}}
$$

where:

$K_{M_{i}}^{\left(G_{i}\right)}$ - degree of mobility of the construction crew unit in i-process for a specific managerial and technological situation $G_{i}$;

$\overline{i, n}$ - workforce of the construction crew unit;

$\overline{i, m}-$ the estimated period of their work in process of construction (month, quarter, year);

$\overline{\gamma, k}--$ number of construction projects;

$V_{i j \gamma}$ - volume of construction and installation works made by the construction crew unit for all construction projects, in rubles;

$K_{G R_{i}}^{\left(P_{1} ; P_{2} ; P_{3}\right)} ; K_{G N_{i}}^{\left(P_{1} ; P_{2} ; P_{3}\right)}$ - mobility and reliability of the construction system, its labor, technical and material resources;

$K_{G R_{i N}}^{\left(P_{1} ; P_{2} ; P_{3}\right)} ; K_{G N}^{\left(P_{1} ; P_{2} ; P_{3}\right)}$ - the same, for usual conditions of the company operation $(0.90 \div 0.95)$. 
The degree of mobility of a construction company and its dependence on the specific conditions when building a facility varies from 'zero' to 'one', i.e. $K_{M_{i}}^{\left(G_{i}\right)}=(0 \div 1)$. The influence of various factors of mobility and uncertainty on the activities of construction companies in these periods changes the degree of mobility towards a decrease. In this case, parameters of the company capacity are variable. For example, the time of their operation at the breaking point increases. This lead to a decrease in the level of usage of the companyaccumulated experience and results in a disruption of the construction processes according to the technological conversion. Loss of time is common both at technological conversions and between them.

In addition, the development of various forms of job management within the framework of process stages provides a certain reduction in time losses in each of stages, but it does not solve the problem as a whole in process of construction, as the time losses increase at the stages between the technological conversions.

Therefore, in order to reduce the total loss of time in the construction and installation processes when operating flows in mobility conditions during transition periods, it is necessary to stimulate development of such forms of labor management at companies as:

- a continuous brigade-district contract in each of the processes (efficient quantity and size of company units and divisions within operating frameworks should be taken into account);

- a collective contract for all construction systems, their construction units and divisions, construction and installation processes.

These contracts should be in place of the low-rise housing construction.

\section{Conclusion}

When determining the perspective directions of using the scientific management for the construction of low-rise residential property, it is necessary to:

1. Identify the type of economic situations, in this case the nature of the company's performance in the construction complex can depend on the main peculiarities of low-rise residential property construction as a whole.

2. Analyze factor space affecting the nature of the company operating in the construction complex.

3. Estimate the possibility of using modern tools and methods for managing the construction of low-rise residential property.

4. Develop a set of measures aimed at increasing the efficiency of building low-rise residential property and the activities of the company as a whole.

Thus, the implementation of inline forms and rotation-based work will allow to modify accordingly the conditions of mobility of construction operations and activities of units, as well as all the main features of the scientific management for the construction of low-rise residential property.

\section{References}

1. Iu.S. Artamonova, Modern Productive Powers 4, 118-123 (2014)

2. M. Buckingham, A. Goodall, Reinventing Performance Management: How One Company is Rethinking Peer Peedback and the Annual Review, and Trying to Design a System to Fuel Improvement. Harvard Business Review (2015)

3. A. Ditillo, Journal of Management Accounting Research 28(3), 49-54 (2016)

4. P.G. Grabovoi, A.B. Kapustkina, Real Estate: Economics, Management 1, 70-77 (2015) 
5. ISO/TR 31004:2013. Risk Management - Guidance for the Implementation of ISO 31000, Technical Report. Geneva, Switzerland: International Organization for Standardization (ISO) (2013)

6. B.B. Khrustalev, Elaborating the Risk management System at the Enterprises of the Regional Investment-Industrial Complex. Monograph (PSUAC, Penza, 2016)

7. B.B. Khustalev, Iu.B. Khustalev, The Main Activities of the Company in Modern Production Conditions, International Conference "Science and Education", 52-60 (2016)

8. B.B. Khustalev, Iu.B. Khustalev, Education and Science in the Modern World. Innovation 1, 296-305 (2017)

9. B.B. Khustalev, A.A. Moiseeva, Modern Economy: Problems and Solutions 6(2), 188198 (2012)

10. B.B. Khustalev, A.A. Moiseeva, Competitiveness in the Global World: Economy, Science, Technology 7(2), 177-182 (2016)

11. B.B. Khustalev, Z.B. Pakhalina, M.E. Spirin, Competitiveness in the Global World: Economy, Science, Technology 8(3), 195-198 (2016)

12. C.M. Lau, G. Scully, Behavioral Research In Accounting 27(1), 25-53 (2015)

13. S. Tranchard, The Revision of ISO 31000 on Risk Management has started, http://www.iso.org/iso/home/news_index/news_archive/news.htm?refid=Ref1963

14. C.E. Bolt-Lee, M. Swain, Journal of Accountancy December, 50-54 (2016)

15. W.G. Bremser, W. P. Wagner, The CPA Journal July, 62-67 (2013) 